\title{
Formulação com aminoácidos totais ou digestíveis em rações com níveis decrescentes de proteína bruta para frangos de corte de 21 a 42 dias de idade
}

\author{
Teresa Herr Viola ${ }^{1}$, Andréa Machado Leal Ribeiro ${ }^{1}$, Carlos Beretta Neto $^{1}$, Alexandre de Mello Kessler ${ }^{1}$ \\ 1 Universidade Federal do Rio Grande do Sul, Faculdade de Agronomia - Departamento de Zootecnia - Av. Bento Gonçalves, 7712 , \\ CEP: 91540-000, Porto Alegre, Rio Grande do Sul.
}

RESUMO - Foram realizados dois experimentos para avaliar a formulação de rações para frangos de corte com redução do nível de proteína bruta (PB) e suplementadas com aminoácidos sintéticos, formuladas com base nos aminoácidos totais - AAT (experimento 1) ou digestíveis - AAD (experimento 2). Os experimentos foram conduzidos no período de 3 a 6 semanas de idade das aves. Em ambos os experimentos, os quatros níveis de PB foram: 20,8; 19,7; 18,6 e 17,5\% PB. No experimento 2, também foram testados outros dois tratamentos com rações contendo 20,8 e 17,5\% de PB e alta digestibilidade (ADig), à base de milho, farelo de soja, amido de milho e proteína isolada de soja. Nos dois experimentos, o consumo de ração não foi afetado pela redução de PB. No experimento 1 , o ganho de peso (GP), a conversão alimentar (CA) e os rendimentos de peito e de coxa foram afetados negativamente pela redução dos níveis de PB, enquanto, no experimento 2 estas variáveis não foram influenciadas. No entanto, em ambos os experimentos, na semana de 21 a 28 dias, o GP e a CA foram influenciados negativamente pela redução dos níveis de PB na ração. Com o decréscimo no nível de PB, a digestibilidade da matéria seca (MS) e da matéria orgânica (MO) aumentou no experimento 2, em virtude da menor inclusão de farelo de soja. Em ambos os experimentos, a retenção relativa de proteína foi superior para rações com baixos níveis de PB. No experimento 2, apesar de os níveis de PB não terem influenciado o desempenho, a ração de ADig proporcionou maior digestibilidade da MO e tendência à maior digestibilidade da MS. As rações com 17,5\% PB e ADig promoveram balanço mais positivo e maior retenção relativa de proteína em comparação às de digestibilidade padrão. Considerando todos os resultados, a formulação de rações com AAD mostrou vantagens em relação aos AAT.

Palavras-chave: aves, metabolismo, proteína ideal, proteína isolada de soja

\section{Total and digestible amino acids formulation in diets with decreasing levels of crude protein for broilers from 21 to 42 days of age}

\begin{abstract}
Two experiments (Exp) were carried out to evaluate diets for broilers formulated with reducing crude protein (CP) level, supplemented with synthetic amino acids, formulated based on total amino acids (TAA) (Exp 1) or digestible AA (DAA) (Exp 2). The experiments conducted in the period from 3 to 6 weeks of age of the birds. In both experiments, the four levels of CP were: 20.8, 19.7, 18.6 and 17.5\% CP. In the Experiment 2, two other treatments were added: diets containing 20.8 and $17.5 \%$ CP and high digestibility (HD), based on corn, soybean meal, corn starch and soy protein isolate. In both experiments, the feed intake was not affected by CP decreasing. In Exp1, weight gain (WG), feed conversion (FC), breast and drumstick yield were negatively affected by CP reduction, meanwhile in Exp 2 those variables were not affected. However, in both experiments, in the week from 21 to 28 days of age, WG and FC were negatively influenced by $\mathrm{CP}$ decrease. As the CP levels decrease, the dry matter (DM) and organic matter (OM) digestibility increased in the Exp 2 , due to the smaller inclusion of soybean meal. In both experiments, the relative protein retention was greater for rations with low CP levels. In Exp 2, although of the different CP levels did not affect the performance, the Hdig diets promoted higher OM digestibility and tended to have higher DM digestibility. The rations with 17.5\%CP level and HDig promoted a more positive protein balance and higher relative protein retention as compared to the standard digestibility. Considering all the results, formulation with DAA showed advantages related to TAA.
\end{abstract}

Key Words: ideal protein, metabolism, poultry, soy protein isolate

\section{Introdução}

Em frangos de corte, as respostas a níveis protéicos na dieta podem variar de acordo com a fase de criação
(Silva et al., 1997), a linhagem (Vieira et al., 2004), o sexo (Wijtten et al., 2004), a presença de fibra na dieta (Gerber et al., 2006) e os níveis de energia (Kolling et al., 2005), entre outros fatores. Os avanços na tecnologia de produção de 
aminoácidos (AA) sintéticos, com a conseqüente redução de seus preços no mercado, têm criado a perspectiva de aumentar progressivamente a aplicabilidade do conceito da proteína ideal nas formulações práticas de rações para aves (Sabino et al., 2001).

Aves em crescimento alimentadas com nível subótimo de PB suplementadas com metionina, lisina e treonina sintéticas mantêm desempenhos similares ou superiores, com menor excreção de nitrogênio em relação aos obtidos com alto nível de proteína bruta - PB (Jensen, 1991; Kidd et al., 2002). Segundo Parr \& Summers (1991), a exigência de aminoácidos essenciais eleva com o aumento da proteína da dieta: a desaminação e a excreção de nitrogênio decorrente do excesso de proteína contribui para a excreção do primeiro aminoácido limitante, aumentando sua exigência. Rações formuladas para minimizar o excesso de proteína, no entanto, podem resultar em menor excreção de aminoácidos essenciais e diminuir os níveis de exigência. Para maior eficiência do uso da proteína, os aminoácidos essenciais devem estar em quantidades que não ultrapassem aquelas exigidas para ótimo crescimento. Um nível ótimo de aminoácidos nãoessenciais também é exigido com o objetivo de garantir relação ideal AA essenciais: não-essenciais (Corzo et al., 2005).

Alguns estudos têm comprovado que as aves não aproveitam bem as frações não-amídicas dos ingredientes comumente utilizados na dieta (Refstie et al., 1999; Wenk \& Messikommer, 1991). Comparando suínos e aves, verifica-se que, enquanto a digestibilidade da MS dos suínos pode chegar a mais de $90 \%$ (Ribeiro et al., 2006), mesmo em fases críticas como o pós-desmame, em aves esse valor não passa de 75\% (Gerber et al., 2006). Essas diferenças se devem à menor capacidade digestiva das aves, sobretudo no intestino grosso, onde podem ser fermentados os polissacarídeos não-amídicos solúveis (PNAs).

Assim, foram realizados dois experimentos para testar a eficiência do uso de rações com níveis reduzidos de PB suplementadas com aminoácidos sintéticos na alimentação de frangos de corte. No experimento 1 , as rações foram formuladas com base nos AAs totais. No experimento 2, a formulação foi realizada com base nos aminoácidoss digestíveis, seguindo o conceito de proteína ideal. Neste segundo experimento, também foram testadas rações com digestibilidade padrão (milho e farelo de soja) e rações de alta digestibilidade (com inclusão de amido de milho e proteína isolada de soja). Em ambos os trabalhos, avaliaram-se o desempenho, o rendimento de carcaça, a digestibilidade da matéria seca e da matéria orgânica e a retenção protéica das rações em frangos de corte de 21 a 42 dias de idade.

\section{Material e Métodos}

Foram realizados dois experimentos (experimentos $1 \mathrm{e}$ 2) no Laboratório de Ensino Zootécnico (LEZO) da UFRGS. No experimento 1 , foram utilizadas 180 aves machos, Ross 308, com quatro tratamentos (níveis de PB) e cinco repetições. No experimento 2, foram usadas 300 aves de mesma linhagem, distribuídas em delineamento inteiramente casualizado com seis tratamentos e cinco repetições por tratamento. Em ambos os experimentos, as aves foram alojadas aos 19 dias de idade, em uma sala com dois exaustores e aspersores no telhado, em gaiolas metabólicas de $0,72 \mathrm{~m}^{2}$. Foram usados 10 animais/gaiola dos 19 aos 27 dias, passando para 9 aves dos 28 aos 34 dias e 8 aves dos 35 aos 42 dias. $\mathrm{O}$ ajuste de número de animais por gaiola visou manter lotação adequada.

Dos 19 aos 21 dias de idade das aves, nos dois experimentos, foram fornecidas água e ração comercial à vontade. Aos 21 dias de idade, os animais foram pesados e redistribuídos com finalidade de deixar as repetições com peso médio semelhante. O período experimental em ambos os experimentos foi de 21 aos 42 dias de idade.

No experimento 1 , foram utilizados quatro tratamentos constituídos de rações fareladas com diferentes níveis de PB (20,8; 19,7; 18,6 e 17,5\%PB) formuladas com base em aminoácidos totais (AAT). As rações do experimento 2 foram peletizadas e formuladas com base em aminoácidos digestíveis (AAD), tendo por princípio o conceito de proteína ideal, contemplando os mesmos níveis de PB do experimento 1. Neste experimento, manteve-se relação mínima de 65\% entre treonina:lisina digestíveis e uma relação constante de $70 \%$ entre metionina+cistina:lisina digestíveis. Em ambos os experimentos, as rações foram formuladas com o objetivo de atender às exigências nutricionais de frangos de corte machos, segundo recomendações de Rostagno et al. (2000) (Tabela 1). As rações foram à base de milho e farelo de soja e consideradas neste trabalho rações de digestibilidade padrão (DigP).

No experimento 2, para os níveis extremos de PB (20,8 e $17,5 \% \mathrm{~PB}$ ), mais dois tratamentos foram incluídos, caracterizados por rações contendo amido de milho e proteína isolada de soja (PIS), a fim de torná-las mais digestíveis e reduzir a quantidade de polissacarídeos não-amídicos, consideradas neste estudo rações de alta digestibilidade (ADig).

Semanalmente, foram avaliados o consumo de ração (CR), o ganho de peso (GP) e a conversão alimentar (CA). Aos 42 dias de idade, foram mensurados os pesos de carcaça, coxa e perna, peito, asa e gordura abdominal de todas as aves do experimento e calculado o rendimento de carcaça e das partes em relação ao peso vivo. 
Tabela 1 - Composição das rações experimentais (experimentos 1 e 2)

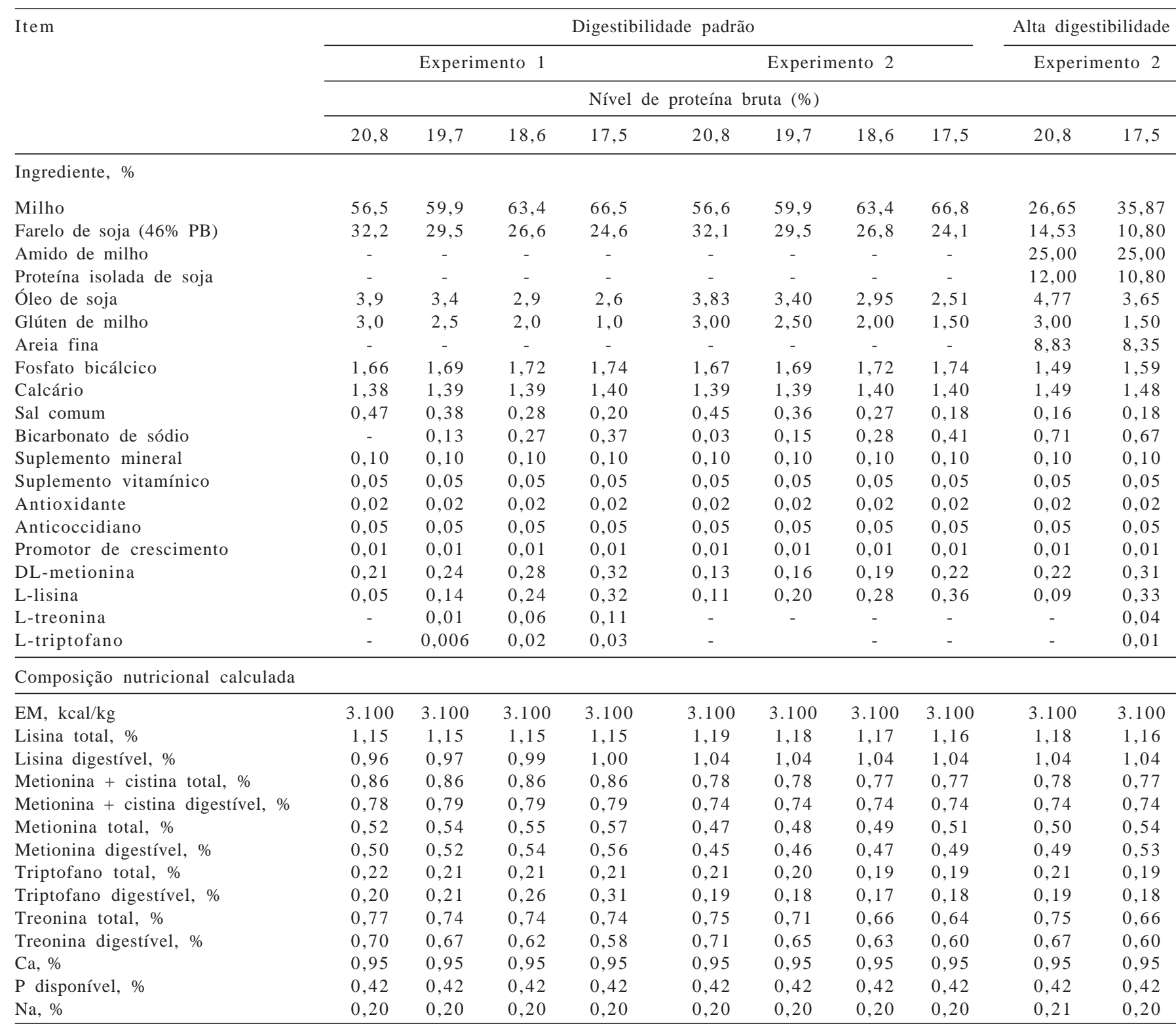

Suplemento mineral (composição por kg de dieta): Se - 0.18 mg; I - 0.38 mg; Fe - 25 mg; Cu - 6 mg; Co - 0,30 mg; Zn - 35 mg; Mn - 72 mg; Suplemento vitamínico (composição por kg de dieta): vit. A - 7.000 IU; vit. D3 - 1.400 IU; vit. E - 20 mg; vit. K3 - 1,5 mg; vit. B1 - 0,6 mg; vit. B2 - 4 mg; vit. B6 0,6 mg; vit. B12 - $10 \mathrm{mcg}$; ácido pantotênico - $9 \mathrm{mg}$; niacina - $23 \mathrm{mg}$; ácido fólico - 0,25 mg; biotina - $20 \mathrm{mcg}$.

Foi medida a digestibilidade (Dig) das rações pelo método de coleta total em todo o período experimental (21 a 42 dias). A coleta foi realizada a cada dois dias. Ração e excretas foram submetidas à análise do percentual de MS, cinzas, nitrogênio e energia bruta, segundo AOAC (1996). Ao final das análises, foram calculados os valores de digestibilidade de matéria seca (DigMS). Na comparação entre rações com diferentes digestibilidades (experimento 2), em virtude do uso de areia na formulação, a Dig da matéria orgânica (DigMO) também foi calculada. A retenção de proteína foi calculada de duas formas: balanço de PB da dieta (BPB), em g/ave/dia, e balanço de proteína em relação à PB ingerida, chamada proteína relativa (BPB/
PBing). Neste trabalho são apresentados os dados do período total (21 a 42 dias) e do período de 21 a 28 dias, em virtude da resposta diferenciada neste período em relação às outras duas semanas experimentais (28 a 35 e 35 a 42 dias).

Os dados de desempenho, de carcaça e de eficiência de utilização do alimento foram submetidos à análise de variância e regressão utilizando-se o módulo GLM do STATISTIX for Windows (1996). Em ambos os experimentos, os quatro níveis de PB tiveram suas médias comparadas pelo teste Tukey, enquanto o efeito contínuo da variação na proteína da dieta foi avaliado pela análise de regressão linear. No experimento 2, as formulações de alta e baixa 
proteína (20,8 e 17,5 \% de PB) e duas digestibilidades foram analisadas em esquema fatorial $2 \times 2$ e os dados submetidos à análise de variância e à comparação pelo teste Tukey.

\section{Resultados e Discussão}

A redução do nível de $\mathrm{PB}$ de 20,8 para $17,5 \%$ não influenciou o consumo de ração $(\mathrm{P}>0,05)$ em ambos os experimentos. Este resultado confirma a observação de Parr \& Summers (1991) e Sabino et al. (2001), que verificaram consumos semelhantes à medida que o nível de PB decresceu. Por outro lado, no experimento 1, houve aumento do ganho de peso com o incremento da $\mathrm{PB}$, resultado não observado no experimento 2 , no qual a probabilidade foi de $9 \%$. Uma explicação para este resultado é o possível esbalanceamento entre os aminoácidos, em decorrência da formulação com base em AAT sem a preocupação de manter relação ótima entre os principais aminoácidos, lisina, metionina+cistina, treonina e triptofano. Outra possibilidade está relacionada à deficiência marginal do quinto e/ou sexto aminoácido limitante (isoleucina e/ou valina), possível em formulações cuja PB dietética é inferior a 19,7\% (Han et al., 1992; Kidd et al., 2004). Em trabalhos realizados por Mendonça \& Jensen (1989), Parr \& Summers (1991) e Silva et al. (1997), comprovou-se que as exigências de aminoácidos essenciais estão relacionadas ao nível de PB da dieta, o que torna mais provável a hipótese de que, em ambos os experimentos, houve desbalanço entre os aminoácidos nas rações de baixa proteína, resultando no aparecimento precoce de deficiência marginal do quinto e/ou sexto aminoácido limitante.

A conversão alimentar também foi significativamente influenciada pela redução de PB no experimento 1 e melhorou com o aumento da PB das rações (Tabela 2). No experimento 2, não houve influência dos níveis de PB na conversão alimentar. Os níveis de lisina digestível nas rações do experimento 1 estavam abaixo do recomendado por Rostagno (2000), o que pode explicar o maior efeito negativo da redução protéica no experimento 1 , ao contrário da formulação com AAD (experimento 2). Sabino et al. (2001), ao utilizarem os mesmos níveis de aminoácidos essenciais (AAE), mas variando a PB, e Moran et al. (1992), ao reduzirem os valores de AAE com a redução de $\mathrm{PB}$, verificaram pior conversão alimentar com a redução da proteína, o que sugere desbalanço nos AAE. Han et al. (1992) encontraram melhor conversão alimentar com a redução do nível de PB na dieta e atribuíram este fato à maior digestibilidade da dieta, em decorrência da maior quantidade de aminoácidos sintéticos. Por outro lado, Parr \& Summers (1991) não encontraram diferença significativa na conversão alimentar com níveis de PB variando de 23 a 20,1\% em rações atendendo às exigências mínimas de AAE.

No período de 21 a 28 dias, observou-se, ao contrário dos demais períodos (28 a 35 e 35 a 42 dias), efeito negativo do decréscimo de PB das rações tanto no ganho de peso como na conversão alimentar, independentemente do tipo de formulação. Pode-se afirmar que o efeito (Tabela 2) foi, em sua maioria, influenciado nesta primeira semana. Os efeitos lineares sobre o ganho de peso e a conversão alimentar evidenciados nos dois experimentos indicam que, nesta fase, a exigência em proteína pode ser ainda mais alta que o usualmente praticado (20\%), em razão da alta taxa de crescimento de tecido magro em frangos de corte nesta idade. Segundo Pophal (2004), a curva de crescimento pode ser alterada quando animais de fases mais jovens são alimentados com rações com diferentes níveis protéicos, o que pode explicar a diferença no ganho de peso na primeira semana experimental, quando a curva de deposição de proteína é mais acentuada que a obtida em idades mais avançadas. Portanto, os níveis de PB nas rações não deveriam ser reduzidos antes dos 28 dias de idade.

No experimento 2, quando comparadas as rações com diferentes digestibilidades (DigP e ADig) (Tabela 4), não foram encontradas diferenças $(\mathrm{P}<0,05)$ para nenhuma das características de desempenho, tampouco interações significativas entre os fatores nível de PB e digestibilidade. O uso, portanto, de ingredientes mais digestíveis, como amido de milho e PIS, não resultou em maior ganho de peso ou melhor conversão alimentar, o que contraria resultados descritos por Wenk \& Messikommer (1991). O uso de ingredientes de alta digestibilidade tem efeito maior nas fases iniciais, quando o sistema digestório e enzimático ainda estão em desenvolvimento. Longo et al. (2005) observaram, em pintos na fase pré-inicial, coeficiente de

Tabela 2 - Desempenho de frangos de corte de 21 a 42 dias de idade alimentados com rações contendo níveis decrescentes de PB formuladas com AAT (experimento 1) ou AAD (experimento 2)

\begin{tabular}{|c|c|c|c|c|c|c|}
\hline \multirow{2}{*}{$\begin{array}{l}\text { Nível PB } \\
(\%)\end{array}$} & \multicolumn{3}{|c|}{ Experimento 1} & \multicolumn{3}{|c|}{ Experimento 2} \\
\hline & CR & $\mathrm{GP}^{1}$ & $\mathrm{CA}^{2}$ & $\mathrm{CR}$ & GP & CA \\
\hline 17,5 & 3.199 & 1.600 & $1,987 a$ & 3.287 & 1.589 & 2,069 \\
\hline 18,6 & 3.198 & 1.646 & $1,934 \mathrm{ab}$ & 3.376 & 1.634 & 2,069 \\
\hline 19,7 & 3.160 & 1.635 & $1,922 \mathrm{ab}$ & 3.376 & 1.594 & 2,121 \\
\hline 20,8 & 3.186 & 1.688 & $1,876 \mathrm{~b}$ & 3.347 & 1.640 & 2,042 \\
\hline
\end{tabular}

AAT = aminoácidos totais, $\mathrm{AAD}$ = aminoácidos digestíveis, $\mathrm{CR}=$ consumo de ração, $\mathrm{GP}=$ ganho de peso, $\mathrm{CA}=$ conversão alimentar .

Médias com letras diferentes diferem $(P<0,05)$ pelo teste Tukey

${ }^{1} \mathrm{GP}=253,112+16,1868 \mathrm{x}, \mathrm{P}<0,09, \mathrm{r}^{2}=0,17$.

$2 \mathrm{GP}=253,112+16,1868 \times, P<0,09, \mathrm{r}^{2}=0,17$.
$2,53452-0,03158 \times, P<0,000, r^{2}=0,59$ 
metabolizabilidade da PIS de apenas 44,5\%. Shelton et al. (2005) observaram que, na comparação com farelo de soja, a proteína isolada prejudicou o consumo dos frangos, que, conseqüentemente, ganharam menos peso. Os autores atribuíram esses resultados à menor densidade da proteína isolada em comparação ao farelo $\left(437 \times 597 \mathrm{mg} / \mathrm{cm}^{3}\right)$ e sugeriram que o enchimento do papo com ingredientes de baixa densidade ocorre antes de a ave ingerir a quantidade adequada de ração para atender às exigências nutricionais, mesmo com rações peletizadas. Neste experimento, não foi observada redução no consumo, embora, no trabalho de Shelton et al. (2005), as rações tenham sido formuladas com o dobro da quantidade de PIS. Shelton et al. (2005) também não descartaram a possibilidade de deficiência de algum aminoácido quando usada PIS.

A digestibilidade da matéria seca (DigMS) foi significativamente alterada pela redução do nível de PB das rações $(\mathrm{P}<0,05)$ no experimento 2 (Tabela 5), mas não no experi-

Tabela 3 - Desempenho de frangos de corte de 21 a 28 dias de idade alimentados com rações contendo níveis decrescentes de PB, formuladas com AAT (experimento 1) ou AAD (experimento 2)

\begin{tabular}{lllllllll}
\hline Nível & PB & \multicolumn{3}{c}{ Experimento } & & & \multicolumn{3}{c}{ Experimento 2} \\
\cline { 2 - 3 } \cline { 7 - 8 }$(\%)$ & $\mathrm{CR}$ & $\mathrm{GP}^{1}$ & $\mathrm{CR}^{3}$ & & $\mathrm{CR}$ & $\mathrm{GP}^{2}$ & $\mathrm{CA}^{4}$ \\
\hline 17,5 & 908 & 536 & $1,694 \mathrm{a}$ & & 934 & $567 \mathrm{~b}$ & $1,646 \mathrm{a}$ \\
18,6 & 889 & 555 & $1,606 \mathrm{ab}$ & & 970 & $608 \mathrm{a}$ & $1,595 \mathrm{ab}$ \\
19,7 & 894 & 571 & $1,568 \mathrm{~b}$ & & 942 & $593 \mathrm{ab}$ & $1,589 \mathrm{ab}$ \\
20,8 & 914 & 590 & $1,550 \mathrm{~b}$ & & 930 & $605 \mathrm{a}$ & $1,535 \mathrm{~b}$ \\
\hline
\end{tabular}

AAT = aminoácidos totais, $A A D=$ aminoácidos digestíveis, $C R=$ consumo de ração, $\mathrm{GP}=$ ganho de peso, $\mathrm{CA}=$ conversão alimentar

Médias com letras diferentes diferem $(P<0,05)$ pelo teste Tukey.

${ }^{1} \mathrm{y}=253,112+16,1868 x, P<0,0221, r^{2}=0,2866$

$2 y=419,362+9,09677 x, P<0,0162, r^{2}=0,2812$

$3 y=2,43668-0,04345 x, P<0,0010, r^{2}=0,4996$.

${ }^{4} y=2,18143-0,03079 x, P<0,0006, r^{2}=0,4929$.

Tabela 4 - Desempenho de frangos de corte no período de 21 a 42 dias de idade alimentados com rações de digestibilidade padrão e alta digestibilidade (experimento 2)

\begin{tabular}{lccc}
\hline Nível de PB (\%) & CR & GP & CA \\
\hline 17,5 & 3312 & 1576 & 2,102 \\
20,8 & 3372 & 1637 & 2,066 \\
\hline Digestibilidade (Dig) & & & \\
\hline Padrão & 3317 & 1615 & 2,055 \\
Alta & 3368 & 1598 & 2,113 \\
\hline Probabilidade & & & \\
\hline PB & 0,23 & 0,12 & 0,46 \\
Dig & 0,30 & 0,65 & 0,25 \\
PB $\times$ Dig & 0,99 & 0,79 & 0,84 \\
\hline
\end{tabular}

$\mathrm{CR}=$ consumo de ração, $\mathrm{GP}=$ ganho de peso, $\mathrm{CA}=$ conversão alimentar . mento 1. Esses resultados estão relacionados principalmente à maior inclusão de farelo de soja nas formulações com maior teor de $\mathrm{PB}$ e, conseqüentemente, à maior participação de carboidratos como estaquiose e rafinose de menor digestibilidade, em relação ao milho, constituído basicamente de amido na sua fração glicídica. Refstie et al. (1999) observaram redução na digestibilidade da MS, do nitrogênio, do amido, da gordura, do cálcio e do fósforo e aumento da viscosidade da dieta com o aumento do farelo de soja nas formulações. Também a maior ou menor quantidade de casca pode influenciar a digestibilidade. Gerber et al. (2006) observaram aumento na digestibilidade da MS de rações formuladas com farelo de soja $48 \%$ de PB em comparação à digestibilidade do mesmo farelo acrescido de casca para atingir 44\% PB.

No experimento 2, quando analisado como fatorial $2 \times 2$, não foram encontradas diferenças na DigMS e DigMO na comparação dos dois níveis de proteína da

Tabela 5 - Coeficiente de digestibilidade da matéria seca em frangos de corte alimentados no período de 21 a 42 dias com rações contendo níveis decrescentes de PB formuladas AAT(experimento 1) ou AAD (experimento 2)

\begin{tabular}{lcc}
\hline Nível de PB (\%) & Experimento 1 & Experimento 2 \\
\hline & Digestibilidade da MS (\%) \\
\hline 17,5 & 70,4 & 65,4 \\
18,6 & 69,9 & 63,0 \\
19,7 & 67,9 & 62,1 \\
20,8 & 69,0 & 61,5 \\
\hline
\end{tabular}

Valor de $\mathrm{P}$

Linear $\quad-\quad 0,0346$

\begin{tabular}{lll}
$\mathrm{R}^{2}$ & - & 0,2251 \\
\hline
\end{tabular}

AAT = aminoácidos totais, $\mathrm{AAD}$ = aminoácidos digestíveis.

Tabela 6 - Digestibilidade da matéria seca e matéria orgânica de rações de digestibilidade padrão e alta digestibilidade em frangos de corte no período de 21 a 42 dias (experimento 2)

\begin{tabular}{lcc}
\hline Nível de PB (\%) & \multicolumn{2}{c}{ Digestibilidade } \\
\cline { 2 - 3 } & MS & MO \\
\hline 17,5 & 63,7 & 70,5 \\
20,8 & 62,3 & 69,1 \\
\hline Digestibilidade (Dig) & & \\
\hline Padrão & 61,8 & $68,6 \mathrm{a}$ \\
Alta & 64,2 & $71,1 \mathrm{~b}$ \\
Valor de P & & \\
PB & 0,27 & 0,23 \\
Dig & 0,08 & 0,04 \\
PB $\times$ Dig & 0,49 & 0,51 \\
\hline
\end{tabular}

Médias com letras diferentes diferem $(P<0,01)$ pelo teste Tukey. 
dieta (Tabela 6). Comparando a DigMS das rações com ADig e DigP, observou-se maior digestibilidade para a dieta ADIg, com probabilidade de 8\%. A alta inclusão de areia fina como diluente da energia e PB nas rações ADig pode ter sido uma das razões da pequena diferença entre as digestibilidades, embora na DigMO não tenha sido evidenciado aumento substancial destas diferenças. Mesmo assim, para a DigMO, foram encontradas diferenças significativas $(\mathrm{P}<0,04)$ no sentido de maior digestibilidade com ADig. Essas respostas podem ser atribuídas à utilização de ingredientes com baixo conteúdo de PNAs, como a proteína isolada de soja e o amido de milho, como observado por Wenk \& Messikommer (1991) e Refstie et al. (1999).

Nos dois experimentos, o balanço de proteína (BPB, $\mathrm{g} /$ ave/dia) foi maior nas aves alimentadas com rações mais protéicas, o que confirma a hipótese de que a suplementação com AAE não foi suficiente para compensar o decréscimo na proteína total, mesmo quando a formulação foi feita com base nos AAD. No experimento 2, entretanto, o acréscimo protéico ocorreu sem aumento significativo do ganho de peso. Também Bartov (1995), em pesquisa com frangos jovens e duas rações com níveis diferentes de proteína e energia, observou que o consumo, a retenção e a excreção absoluta de $\mathrm{N}$ foram significativamente maiores nas aves alimentadas com a dieta de alta proteína.

A retenção relativa de proteína em ambos os experimentos não foi influenciada pela redução protéica da dieta, resultado que contraria diversos trabalhos (Fancher \& Jensen, 1989; Bartov, 1995; Kolling et al., 2005) em que a eficiência de utilização da proteína consumida é inversamente proporcional ao consumo da proteína.

No experimento 2 , analisando o fatorial $2 \times 2$, verificou-se interação significativa entre níveis de PB e digestibilidade da dieta, tanto na retenção de proteína absoluta quanto na retenção relativa (Tabela 8). A dieta com 17,5\% PB e DigP resultou em menor retenção em proteína, no entanto, a dieta $17,5 \%$ PB e ADig não diferiu, quanto à retenção absoluta, da dieta 20,8\% com DigP. Para a retenção relativa, a dieta 17,5\%PB e ADig foi melhor que aquelas com 20,8\% $\mathrm{PB}$, independentemente de suas digestibilidades. Maior eficiência de retenção de proteína em rações com menor PB foi observada por Kolling et al (2005) e pode ser atribuída ao aumento na relação energia:proteína e, portanto, ao aumento da disponibilidade de EM para a síntese protéica. No entanto, o fato de o tratamento $17,5 \% \mathrm{~PB}$ e DigP ter apresentado a menor resposta em retenção protéica indica fortemente que a digestibilidade da PB da dieta também é um fator limitante e que somente na dieta 17,5\% e ADig houve disponibilidade suficiente de aminoácidos para
Tabela 7 - Balanço da proteína bruta (BPB, g/ave/dia) e balanço relativo (BPB/PBing, \%) em frangos de corte alimentados no período de de 21 a 42 dias com rações contendo níveis decrescentes de PB formuladas AAT(experimento 1) ou AAD (experimento 2)

\begin{tabular}{lcclcc}
\hline \multirow{2}{*}{ Nível de PB (\%) } & \multicolumn{2}{c}{ Experimento 1 } & & \multicolumn{2}{c}{ Experimento 2 } \\
\cline { 2 - 3 } \cline { 5 - 6 } & BPB $^{1}$ & BPB/PBing & & BPB $^{2}$ & BPB/PBing \\
\hline 17,5 & 14,5 & 57,9 & & 13,6 & 50,3 \\
18,6 & 15,2 & 57,2 & & 13,5 & 45,7 \\
19,7 & 15,3 & 54,9 & & 15,5 & 49,8 \\
20,8 & 16,9 & 56,3 & & 16,1 & 49,5 \\
\hline
\end{tabular}

${ }^{1} \mathrm{BPB}=2,44421+0,68306 x ; R^{2}=0,40 ; P<0,003$.

$2 \mathrm{BPB}=-1,97822+0,87290 x ; R^{2}=0,47 ; P<0,001$

que a resposta fosse beneficiada pelo aumento na relação EM:PB.

O rendimento de peito e coxa no experimento 1 foi negativa e significativamente $(\mathrm{P}<0,05)$ afetado pela redução do nível de PB das rações (23,4; 23,5; 23,8 e 24,0\% e 12,5; 13,$3 ; 13,0$ e $13,3 \%$, respectivamente). Os demais cortes e o rendimento total de carcaça, tampouco o rendimento de gordura abdominal, não foram influenciados significativamente pelo decréscimo da proteína. Cahaner et al. (1995) também observaram melhora no rendimento de peito nas aves com alta PB, mas também observaram aumento da gordura abdominal das aves com baixa PB. Smith \& Pesti (1998) também observaram que menores níveis de PB resultaram em maior gordura abdominal, mas não influenciaram o rendimento de carcaça das aves. Dari et al. (2005) observaram mesmo rendimento de carcaça, mas maior gordura abdominal nas aves alimentadas com rações contendo 18,2\% de PB em relação às rações com $20 \%$ PB, formuladas com base em AAT.

No experimento 2, nenhum resultado de rendimento foi significativo. Resultados obtidos por Fischer (1993) e Pack \& Schutte (1995) indicam que os níveis de aminoácidos sulfurados e de lisina são maiores para rendimento de músculo de peito que os propostos para a máxima conversão alimentar. Considerando que neste experimento as relações entre os aminoácidos foram mantidas constantes, poucas diferenças ocorreriam no rendimento de carcaça e dos cortes. Portanto, a formulação com base em aminoácidos totais apresentou diferenças mais marcantes no rendimento de carne de peito em comparação à formulação com base em aminoácidos digestíveis. Este resultado contraria os descritos por Dari et al. (2005), que não encontraram influência da formulação com AAT e AAD sobre o rendimento de peito das aves.

Comparando as formulações de DigP e ADig, no experimento 2 não foram encontrados efeitos do nível de PB, da 
Tabela 8 - Balanço da proteína bruta (BPBg/ave/dia) e balanço relativo (BPB/PBing- \%) em frangos de corte alimentados no período de 21 a 42 dias com rações de digestibilidade padrão e alta digetibilidade (experimento 2)

\begin{tabular}{llc}
\hline Nível de PB (\%) & BPB & BPB/PBing \\
\hline 17,5 & 15,7 & 57,5 \\
20,8 & 18,0 & 56,6 \\
\hline Digestibilidade (Dig) & & \\
\hline Padrão, DigP & 15,4 & 53,2 \\
Alta, ADig & 18,3 & 60,9 \\
\hline Interação & & \\
\hline 17,5 DigP & $13,7 \mathrm{a}$ & $50,3 \mathrm{c}$ \\
17,5 ADig & $17,8 \mathrm{bc}$ & $64,8 \mathrm{a}$ \\
20,8 DigP & $17,1 \mathrm{~b}$ & $56,2 \mathrm{~b}$ \\
20,8 ADig & $18,9 \mathrm{c}$ & $57,0 \mathrm{~b}$ \\
\hline Valor de P & & \\
\hline PB & 0,0001 & 0,38 \\
Dig & 0,0001 & $<0,0001$ \\
PB $\times$ Dig & 0,02 & $<0001$ \\
\hline
\end{tabular}

Médias com letras diferentes diferem $(P<0,02)$ pelo teste Tukey.

digestibilidade da ração e de suas interações sobre o rendimento de carcaça e cortes das aves. Griffiths et al. (1977) observaram que a inclusão de proteína de baixa qualidade (farinha de penas) é tão efetiva quanto a proteína de alta qualidade (farelo de soja + DL-metionina) na redução da gordura abdominal, todavia, Dari et al. (2005) encontraram menor rendimento de peito e maior gordura abdominal em rações com ingredientes de menor digestibilidade dos aminoácidos, como farelo de trigo, farinha de penas e farinha de carne, em comparação a rações à base de milho e farelo de soja. Como neste experimento as diferenças em digestibilidade estiveram relacionadas mais aos carboidratos que à fração protéica, as comparações com trabalhos enfatizando digestibilidade e aminoácidos devem ser feitas com cautela.

\section{Conclusões}

Frangos alimentados com rações à base de aminoácidos totais tiveram menor ganho de peso e menor rendimento de peito e coxa com o decréscimo de PB da dieta, apesar da suplementação com os quatro primeiros aminoácidos limitantes. No entanto, os mesmos níveis de PB não influenciaram estes parâmetros quando as rações foram formuladas com base nos aminoácidos digestíveis. A digestibilidade das rações foi melhor com níveis mais baixos de $\mathrm{PB}$, em razão da menor quantidade de farelo de soja. Rações com distintas digestibilidades não influenciaram o desempenho das aves, mas a dieta de alta digestibilidade favoreceu a retenção protéica, sobretudo com rações contendo baixo nível de PB.

\section{Literatura Citada}

ASSOCIATION OF OFFICIAL AGRICULTURAL CHEMISTS AOAC. Offical methods of analysis. 16.ed. Gaitesburg: AOAC International, 1996. v.2.

BARTOV, I. Differential effect of age on metabolisable energy content of high protein-low energy and low protein-high energy diets in young broiler chicks. British Poultry Science, n.4, v.36, p.631-643, 1995 .

CAHANER, A.; PINCHASOV, Y.; NIR, I. Effects of dietary protein under high ambient temperature on body weight, breast meat yield, and abdominal fat deposition of broiler stocks differing in growth rate and fatness. Poultry Science, n.6, v.74, p.968975, 1995.

COON, C.N.; LESKE, K.L.; AKAVANICHAN, O. et al. Effect of oligosaccharide-free soybean meal on true metabolizable energy and fiber digestion in adult roosters. Poultry Science, v.69, p.787-793, 1990.

CORZO, A.; FRITTS, C.A.; KIDD, M.T. et al. Response of broiler chicks to essential and non-essential amino acid supplementation of low crude protein diets. Animal Feed Science and Technology, v.118, p.319-327, 2005.

DARI, R.L.; PENZ, A.M.; KESSLER, A.M. et al. Use of digestible amino acids and the concept of ideal protein in feed formulation for broilers. Journal of Applied Poultry Research, v.14, n.2, p.195-203, 2005.

FANCHER, B.I.; JENSEN, L.S. Influence on performance of three to six week old broilers of varying dietary protein contents with supplementation of essential amino acid requirements. Poultry Science, n.1, v.68, p.113-123, 1989.

FISHER, C. Impact of amino acids on carcass quality in broilers. In: ARKANSAS NUTRITION CONFERENCE, 1993 , Fayeteville. Proceedings... [S.l.:s.n.], 1993. p.33-45.

GERBER, L.F.P; PENZ, A.M.; RIBEIRO, A.M.L.. Efeito da composição do farelo de soja sobre o desempenho e o metabolismo de frangos de corte. Revista Brasileira Zootecnia, n.4, v.35, p.1359-1365, 2006.

GRIFFITHS, L.; LESSON, S.; SUMMERS, J.D. Fat deposition in broilers: Effect of dietary energy to protein balance, and early life caloric restriction on productive performance and abdominal fat pad size. Poultry Science, n.4, v.56, p.638-646, 1977.

HAN, Y.; SUZUKY, H.; PARSONS, C.M. et al. Amino acid fortification of a low-protein corn and soybean meal diets for chicks. Poultry Science, v.71, p.1168-1178, 1992.

HEO, K.N.; HAN, I.K.; SHIN, I.S. et al. Protein sparing effect and amino acid digestibilities of supplemental lysine and methionine in weanling pigs. Asian-Australian Journal Animal Science, v.8, p.393-345, 1995.

JENSEN, L.S. Are peptides needed for optimum nutrition? Feed Management, v.42, n.8, p.37-40, 1991.

KERR, B.J.; KIDD, M.T. Amino acid supplementation of lowprotein broiler diets: glutamic acid and indispensable amino acid supplementation. Journal of Applied Poultry Research, v.8, p.298-309, 1999.

KIDD M.T.; ZUMWALT C.D.; CHAMBLEE D.W. et al. Broiler growth and carcass responses to diets containing L-threonine versus diets containing threonine from intact protein sources. Journal Applied Poultry Research, v.11, p.83-89, 2002.

KIDD M.T.; BURNHAM D.J.; KERR, B.J. Dietary isoleucine responses in male broiler chickens. British Poultry Science, v.45, p.67-75, 2004.

KOLLING, A.V.; KESSLER, A.M.; RIBEIRO, A.M.L. Desempenho e composição corporal de frangos de corte alimentados com diferentes níveis de proteína e de aminoácidos ou com livre escolha das dietas. Revista Brasileira de Zootecnia, v.34, n.1, p.98-103, 2005.

LONGO, F.A.; MENTEN, J.F.M.; PEDROSO, A.A. et al. Diferentes fontes de proteína na dieta inicial de frangos de corte. Revista Brasileira de Zootecnia, v.34, n.1, p.112-122, 2005. 
MENDONÇA, C.X.; JENSEN, L.S. Influence of protein concentration on the sulphur-containig amino acid requeriment of broiler chickens. British Poultry Science, v.30, p.889-898, 1989.

MORAN, E.T.; BUSHONG JR., R.D.; BILGILI, S.F. Reducing dietary crude protein for broilers while satisfying amino acid requirement by least-cost formulation: live performance, litter composition and yield of fast-food carcass cuts at six weeks. Poultry Science, v.71, p.1687-1694, 1992.

PACK, M.; SCHUTTE, J.B. Sulfur amino acid requirement of broiler chicks from fourteen to thirty-eight days of age. 2 . Economic evaluation. Poultry Science, v.74, p.488-493, 1995.

PARR, J.F.; SUMMERS, J.D. The effect of minimizing amino acid excesses in broiler diets. Poultry Science, v.70, p.1540-1549, 1991.

POPHAL, S. Características de crescimento de dois cruzamentos de frangos de corte recebendo dietas com diferentes níveis de lisina na primeira semana de vida. Porto Alegre: Universidade Federal do Rio Grande do Sul, 2004. 174p. Tese (Doutorado em Zootecnia) - Universidade Federal do Rio Grande do Sul, 2004.

REFSTIE, S.; SVIHUS, B.; SHEARER, K.D. e al. Nutrient digestibility in Atlantic salmon and broiler chickens related to viscosity and non-starch polysaccharide content in different soyabean products. Animal Feed Science Technology, v.79, p.331-345, 1999.

RIBEIRO, A.M.L.; PEDROZZO, S.A.; KESSLER, A.M. Relações treonina:lisina no desempenho e metabolismo de leitões desmamados. Revista Brasileira Agrociência, v.12, n.2, p.207-212, 2006.

ROSTAGnO, H.S. Tabelas brasileiras para aves e suínos: composição de alimentos e exigências nutricionais. 2.ed. Viçosa, MG: Universidade Federal de Viçosa, 2000. 63p.
SABINO, H.F.N.; SAKOMURA, N.K.; NEME, R. et al. Efeito do nível protéico da ração sobre o desempenho de frangos de corte na fase de crescimento. In: REUNIÃO ANUAL DA SOCIEDADE BRASILEIRA DE ZOOTECNIA, 38., 2001, Viçosa, MG. Anais... Viçosa, MG: Sociedade Brasileira de Zootecnia, 2001. p.832-834.

SILVA, M.A.; ALBINO, L.F.T.; ROSTAGNO, H.S. et al. Exigências Nutricionais em metionina+cistina para pintos de corte, em função do nível de proteína bruta da ração. Revista Brasileira de Zootecnia, v.26, p.357-363, 1997.

SHELTON, J.L.; DEAN, D.W.; SOUTHERN, L.L. et al. Effect of protein and energy sources and bulk density of diets on growth performance of chicks. Poultry Science, v.84, p.1547-1554, 2005.

SMITH, E.R.; PESTI, G.M. Influence of broiler strain cross and dietary protein on the performance of broilers. Poultry Science, v.77, p.276-281, 1998.

STATISTIX for Windows. User's manual. Analytical Software, Tallahassee: 1996. 333p.

VIEIRA, S.L.; LEMME, A.; GOLDENBERG, D.B. et al. Responses of growing broilers to diets with increased sulfur amino acids to lysine rations at two dietary protein levels. Poultry Science, v.83, p.1307-1313, 2004.

WENK, C.; MESSIKOMMER, R. Utilization of the energy of soyabean and sorghum hulls for growth in growing chickens. In: EUROPEAN ASSOCIATION FOR ANIMAL PRODUCTION SYMPOSIUM, 12., 1991, Kartause Ittingen. Proceedings... Kartause Ittingen: [s.n.], 1991. p.194-197.

WIJTTEN, P.J.A.; LEMME, A.; LANGHOUT, D.J. Effects of different dietary ideal protein levels on male and female broiler performance during different phases of life: single phase effects, carryover effects, and interactions between phases. Poultry Science, v.83, p.2005-2015, 2004. 